\title{
INOVAÇÃO COMO CONSENSO
}

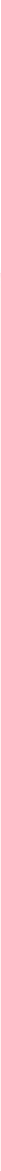




\section{RESUMO}

Este texto é a reprodução da primeira parte de um trabalho mais amplo, realizado a pedido da Cepal, que foi publicado em 2010. O autor faz uma resenha de todo o debate sobre a inovação tecnológica no Brasil a partir de 1990. Com a singular competência que sempre caracterizou a vida acadêmica de Fabio Erber, ele conseguiu sistematizar o debate brasileiro sobre as características e determinantes do desempenho das empresas atuantes no país em matéria de inovação tecnológica.

Palavras-chave: inovação, desenvolvimento, transformação tecnológica.

\section{ABSTRACT}

This text reproduces the first part of a longer paper written by professor Fabio Erber upon a request by ECLAC [Economic Commission for Latin American and the Caribbean]; and which was published in 2010. In this article the author presents a summary of all the debating on technological innovation in Brazil from 1990 on. Drawing on the unique expertise which has always been the hallmark of his academic life, Fabio Erber has managed to systematize the Brazilian debate on the characteristics and determinants of the performance of the country's companies as regards to technological innovation.

Keywords: innovation, development, technological transformation. 


\section{TRANSFORMAÇÃO TECNOLÓGICA}

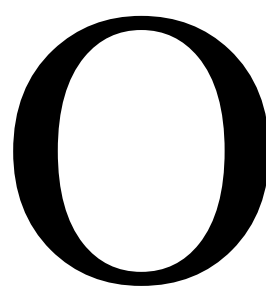

último quarto de século foi um período de grandes transformações tecnológicas, manifestas na difusão e no aperfeiçoamento do paradigma eletrônico, que se tornou ubíquo, englobando todos os setores da economia - da agricultura às "indústrias criativas" -, sintetizado na expressão tecnologias de informação e comunicação (TIC); na consolidação do paradigma da biotecnologia e na emergência da nanotecnologia. A intensidade, a rapidez e a difusão mundial - pelo menos no uso - dessas tecnologias inseriram o tema "inovação tecnológica" na agenda positiva de tomadores de decisão privados e públicos, tornando-o um símbolo de "modernidade" dotado de prestígio e de forte capacidade legitimadora.

\section{LEGITIMIDADE ACADÊMICA}

Se os conceitos tivessem analogias urbanas, a inovação poderia ser assemelhada a uma dessas praças em forma de estrela, como a De Gaulle em Paris e a Raul Soares em Belo Horizonte, as quais aportam avenidas vindas de diversos lugares, juntam-se $\mathrm{e}$, a seguir, continuam seu percurso rumo a destinações divergentes.

A partir dos anos 1990, quatro avenidas, com histórias distintas, tornaram a inovação um lócus de convergência teórica em economia. Foge ao propósito deste artigo uma revisão detalhada desse processo, mas é relevante registrá-lo para entender a literatura brasileira.

A avenida de traçado mais linear é a da teoria do comércio internacional ${ }^{1}$. Nos anos 1960, em um contexto de crescente competição oligopolista entre os países capitalistas avançados, trabalhos seminais como os de Posner (1961) e Linder (1961) mostravam que o comércio era criado por inovações tecnológicas, mudando a natureza das vantagens comparativas, que deixavam de ser "dadas" pela dotação de fatores e passavam a ser "construídas", inclusive mediante a intervenção deliberada dos estados nacionais. Logo a seguir, as teorias de ciclo de produto (Vernon, 1966) ampliariam o alcance do progresso técnico, passando a abarcar o investimento direto no exterior.

O resgate dos "fatores de produção" canônicos foi feito por meio da ampliação do conceito de "capital" - esse fator estaria incorporado na capacitação das pessoas, no valor capitalizado do conhecimento produzido pela pesquisa e desenvolvimento, etc. Tal ampliação implicava o estudo da alocação do capital entre as diversas formas que este poderia assumir, que seriam diferenciadas entre países, segundo suas características econômicas e institucionais (Johnson, 1968, 1970).

No entanto, conforme aponta o próprio Johnson (1970), a explicação do comércio internacional via diferenciação tecnológica era mais consentânea com a percepção dos policy-makers sobre a competição dentro e entre os estados industriais modernos. Assim, a percepção de que as vantagens comparativas são "construídas", com a forte participação dos estados nacionais nesse processo, tornou-se hegemônica.

Dominava à época a visão de que o progresso técnico era resultado de um processo linear, que tinha sua origem na pesquisa científica. Significante da legitimidade do tema é o fato de terem os governos dos países da Organização para a Cooperação e Desenvolvimento Econômico (OCDE) iniciado a mensuração sistemática dos esforços nacionais de pesquisa e desenvolvimento (P\&D) já em 1963 - data da primeira edição do Manual Frascatti. A seguir, a intensidade tecnológica dos produtos tornar-se-ia uma das formas canônicas de categorizar o comércio internacional.

A segunda avenida, mais tortuosa, é a das teorias do crescimento econômico. Para os nossos propósitos, basta, porém, lembrar que, na segunda metade dos anos 1980, a inovação tornara-se o elemento central da explicação do crescimento.
FABIO STEFANO

ERBER, economista, foi professor do Instituto de Economia da Universidade Federal do Rio de Janeiro (UFRJ) e membro da diretoria do Centro Internacional Celso Furtado.

Este texto é um excerto de artigo publicado em 2010 na série Textos para Discussão Cepal-Ipea n⿳⺈ 17, tendo sido elaborado para a Cepal, dentro das atividades conjuntas promovidas peloacordo de cooperação técnica com o Ipea, que autorizaram a sua republicação na Revista USP. As opiniões e recomendações apresentadas são de responsabilidade do autor, não representando necessariamente as das instituições citadas.

1 Ver De Negri (2005) para uma revisãomais ampla da literatura, inclusive a mais moderna.Meu propósito limita-se a assinalar a formação de certos consensos básicos. 
2 A mesma fonte que examina o caso brasileiro sob essa ótica apresenta uma revisão da literatura recente.

3 Rodriguez, Dahlman e Salmi (2008) é uma publicação do Banco Mundial. Dahlman e Frischtak são consultores do banco.

4 Para uma visão crítica da hélice tripla, na literatura brasileira, ver Dagnino (2004).

5 Romer (1990, p. 21) apontava como um dos principais resultados da teoria do crescimento endógeno a possibilidade de discutir "as principais questões de política relativas ao crescimento. Em um país em desenvolvimento como as Filipinas, quais são os melhores arranjos institucionais para ganharacesso ao conhecimento que já existe no resto do mundo? Em um país como os Estados Unidos, quais são os melhoresarranjosinstitucionais para encorajara produção e uso do conhecimento?".

6 Lakatos (1970) propõe que os programas de pesquisa científicos são constituídos por um núcleo central, axiomático e irrefutável, e por um cinturão protetor, que contém as hipóteses auxiliares e os procedimentos adotados para selecionar e resolver os problemas, sujeito, portanto, a alterações. Um programa de pesquisas é progressivo se oseu conteúdo empírico se amplia, mediante transformações no cinturão protetor.

7 Ver em Romer (1990), as diversas referências amistosas ao programa evolucionista.
No mainstream, o progresso técnico, antes visto como exógeno ao sistema econômico, foi internalizado, reconhecendo-se que a tecnologia não é um bem público que resulta de investimentos feitos por empresas, visando a rendas diferenciadas e que, portanto, nos mercados tendem a prevalecer condições de concorrência imperfeita (Romer, 1990). O crescimento econômico seria resultante da expansão do capital físico, do capital humano - trabalho ajustado por educação, treinamento e habilidades - e de um conjunto de elementos, como a adoção de novas tecnologias e métodos de gestão mais eficientes. $\mathrm{O}$ aumento da produtividade total dos fatores (PTF), que resulta da amálgama dos vários tipos de capital e da inovação, seria o "verdadeiro propulsor das economias" (Rodriguez, Dahlman \& Salmi, 2008, p. 65) ${ }^{2}$.

Nessa perspectiva, "as forças geminadas da globalização e dos avanços tecnológicos [notadamente das TICs] vêm, de fato, impulsionando a atual revolução do conhecimento" (Dahlman \& Frischtak, 2005, p. 151). A economia global tornou-se a economia do conhecimento e a revolução se manifesta de muitas maneiras:

“[...] laços mais estreitos entre Ciência e Tecnologia; maior importância da inovação para o crescimento econômico e a competitividade; maior importância da educação e da aprendizagem por toda a vida; e mais investimento em bens intangíveis $(\mathrm{P} \& \mathrm{D}$, programas de computador e educação), em uma proporção ainda maior do que os investimentos em capital fixo" (Dahlman \& Frischtak, 2005, p. 151).

O apoio do Banco Mundial e de outras instituições internacionais dotadas de poder contribuiu fortemente para difundir essa visão ${ }^{3}$.

A ideia de economia do conhecimento tem sido frequentemente associada a mudanças nas relações entre empresas, universidades e governo. A interação entre os três tipos de instituições daria origem a uma "hélice tripla”, na qual: a empresa seria o lócus de produção; o governo, a fonte de relações contratuais que garantiriam trocas e interações estáveis; e a universidade, a fonte de novo conhecimento e tecnologia, o princípio gerador das economias baseadas no conhecimento. $\mathrm{Na}$ hélice tripla, a universidade assumiria um papel mais empresarial, promovendo a inovação por meio da sua interação com as duas outras "pás" (Etzkowtiz \& Melo, 2004).

Embora seus proponentes reconheçam que o conceito da hélice tripla tenha sido desenvolvido ex post, baseado no que ocorria nos países avançados, eles sustentam que pode ser usado como um "conceito ex-ante, como uma ferramenta estratégica para abrir caminhos para um processo de emparelhamento, com o fim último de criar uma sociedade de aprendizado" (Etzkowtiz \& Melo, 2004, p. 161). Enfatizando a globalização, acreditam que a hélice tripla "está emergindo como um formato comum que transcende as fronteiras nacionais"4.

A relevância de fatores institucionais para ampliação e aperfeiçoamento do capital físico e humano e da PTF, ressaltada desde o início pelos teóricos do crescimento endógeno ${ }^{5}$, encontrava também apoio nos estudos históricos da nova economia institucional, que enfatizavam as instituições que fomentavam a inovação e reduziam os custos de transação (North, 1990). O Banco Mundial viria a sintetizar esses fatores institucionais sob a denominação de "clima de investimento" (condições macroeconômicas, Estado de Direito, política de competitividade, governabilidade e segurança) (Rodriguez, Dahlman \& Salmi, 2008) e, tendo implicitamente uma formulação de "tipos ideais", de natureza universal, para essas instituições, estabelece comparações entre os países e incita-os a estabelecer instituições "corretas" - outra faceta da globalização.

Conforme veremos a seguir, alguns estudos importantes sobre a inovação no Brasil adotam a perspectiva anteriormente sumariada.

$\mathrm{Na}$ mesma época em que o programa de pesquisas ${ }^{6}$ do crescimento endógeno vinha à luz, na outra calçada da avenida das teorias de crescimento desenvolvia-se o programa evolucionista neo-schumpeteriano ${ }^{7}$. Além de reiterar a centralidade da inovação para 
o crescimento econômico, herdada do seu padrinho, esse programa apresenta outro entendimento do processo de inovação.

Partindo do axioma da diversidade entre firmas, com base nas teorias de Penrose (1959), os fundamentos microeconômicos do programa levavam à valorização da inovação ${ }^{8}$. No entanto, ao abandonar a noção de "agente representativo", tornavam necessários outros conceitos que fugissem da síndrome de Gertrude Stein: "uma empresa é uma empresa, é uma empresa”. Classificações de atividades ao nível muito desagregado tampouco ofereciam uma solução.

Esta foi encontrada em conceitos mesoeconômicos, como os "paradigmas tecnológicos" de Dosi (1982) e os "regimes tecnológicos" de Malerba e Orsenigo (1997). Apesar da utilidade desses conceitos, a taxionomia de setores segundo suas características tecnológicas, proposta por Pavitt (1984), tornou-se a mais difundida.

Elaborada a partir de um grande banco de dados sobre inovações, organizado no Science Policy Research Unit da Universidade de Sussex, no Reino Unido ${ }^{9}$, a taxionomia de Pavitt era consistente com estudos de fluxos de inovação feitos com base em dados de patentes (Scherer, 1982) e análises históricas (Landes, 1969) e apontava que os diversos grupos de setores não só tinham diferentes taxas de inovação, utilizando tipos de conhecimento distintos, como desempenhavam papéis distintos na difusão intersetorial de inovações. Ou seja, os proverbiais potato chips e computer chips não diferiam apenas na intensidade de inovações, na taxa de crescimento e no potencial exportador - sua presença e força em dada estrutura industrial afetava a dinâmica de toda essa estrutura.

No Brasil, a literatura dos anos 1990 (Erber, 1992; Coutinho \& Ferraz, 1994; Ferraz, Kupfer \& Hague-Nauer, 1996), utilizando essas informações, propôs que, vistos do ângulo do fluxo de inovações, os setores podiam ser divididos em motores, que geram as principais, baseados em ciência - por exemplo, a eletrônica -, receptores, cuja demanda é atendida principalmente pela oferta de outros setores (bens de consumo durável), e intermediários, de demanda, suprida, em parte, por esforços internos - principalmente inovações incrementais - e, em parte - as mais radicais - , por aquelas geradas nos setores motores. Os setores intermediários (por exemplo, bens de capital e insumos de produção) atuam como supridores de inovações entre si e, notadamente, para os receptores. A essa taxionomia setorial, Erber (1992) associava uma taxionomia de intervenções estatais que seguia a relação risco/custo da inovação ${ }^{10}$.

A complexidade do processo de inovação seria enriquecida a partir da segunda metade dos anos 1980 com a adição da dimensão do aprendizado, adquirido por meio de produção, uso e inovação. Agentes econômicos, dotados de racionalidade restringida, informação incompleta e enfrentando incerteza, ampliavam suas competências, nas cadeias produtivas, por meio da produção e do uso de bens e serviços e da interação com consumidores e fornecedores. Ou seja, era importante estudar como relações duradouras e padrões de interação e dependência estabeleciam-se, evoluíam e dissolviam-se com o correr do tempo (Lundvall, 2007). Como, além de empresas, participam desse processo outros tipos de instituições, não empresariais, a dimensão institucional resultava ampliada, incorporando, explicitamente, a ação do Estado.

A dimensão do aprendizado tinha outras implicações. Em primeiro lugar, apontava para a importância dos conhecimentos tácitos e específicos a cada empresa e à cadeia produtiva, reforçando suas diferenças. Em segundo lugar, ampliava o leque de atividades inovadoras e dos seus componentes, reconhecendo-se a importância, por exemplo, de modificações organizacionais. Em terceiro lugar, mostrava que a inovação tendia a ser ubíqua - mesmo setores pouco intensivos em P\&D introduziam inovações, sem que isso falsificasse (no sentido popperiano) a observação de que havia uma hierarquia setorial em termos de geração e difusão de inovações no âmbito da estrutura econômica. Em quarto lugar, apontava para a natureza sistêmica do processo de inovação.
80 programa neo-schumpeteriano sempre deu ênfase aos fenômenos de oferta, enfocando empresas. A visão de produtos de Lancas ter (1966), em que estes são definidos por um conjunto de atributos, reforça a diversidade pelolado da demanda e é complementar à sua visão de empresa.

9 As categorias de setores de Pavitt são: "dominados pelos fornecedores"; "intensivos em produção", subdivididos em "intensivos em escala" e "fornecedores especializados de equipamentos" $\mathrm{e}$ "baseadosna ciência".

10Para os setores receptores, em que a relação risco/custo seria relativamente mais baixa, a intervenção seria essencialmente de normas relativas a produtose processos para os setores motores, em que a relação risco/custo seria alta, a intervenção teria uma natureza estruturante, comoEstado criando simultaneamente o mercado e os seusfornecedores, enquanto nos setores intermediários a intervenção seria de fomento, quando o Estado define incentivos para certas atividades e condicionalidades para o uso dessesincentivos, masdeixaaomercado a estruturação final do setor. A taxionomia é evidentemente datada, tendo por referência o Estado desenvolvimentista. 
11 No sentido de que um fenômeno não pode ser reduzido às características de seus componentes.

12 Na literatura brasileira, há boas revisões do conceito de sistemas de inovação em Viotti (2001), Cassiolato e Lastres (2005), Villaschi (2005) e Albuquerque (2007). Ver Arocena e Sutz (2003) para uma discussão das limitações do conceito quando aplicado aos países em desenvolvimento.
A combinação dessas características mostrava a importância de pensar a inovação como resultado de sistemas específicos, dotados de características como path-dependence e lock-in, histerese, emergência ${ }^{11}$, retroalimentação e auto-organização. Assim, o modelo de passagem linear do conhecimento, da ciência para o novo produto ou processo por meio do desenvolvimento tecnológico (a P\&D), dava lugar a uma visão de inovação mais complexa e diversificada.

Dependendo do foco de análise, tal especificidade pode ser vista pela ótica nacional (Freeman, 1995; Lundvall, 1992; Nelson, 1993), setorial (Malerba \& Orsenigo, 1997) ou regional (Cassiolato \& Lastres, 2003), pois, conforme aponta Lundvall (2007), um dos pais do conceito de "sistemas de inovação", em uma recente revisão ${ }^{12}$, é, essencialmente, um focusing device. À diferença da abordagem da hélice tripla e do tecnoglobalismo, a visão de sistemas de inovação, em qualquer dos seus focos, enfatizava a especificidade do sistema (Cassiolato \& Lastres, 2005).

A perspectiva ampliada da inovação, anteriormente esboçada, requeria instrumentos de mensuração distintos daqueles proporcionados pelo Manual Frascatti. Assim, a OCDE passou, em 1992, a novas formas de mensuração, expressas no Manual de Oslo, que serviu de base às pesquisas nacionais do Instituto Brasileiro de Geografia e Estatística (IBGE) e da Fundação Sistema Estadual de Análise de Dados (Seade), em São Paulo, cujos dados alimentam grande parte dos estudos a seguir resenhados.

Finalmente, a última avenida de teoria que convergia para a Praça da Inovação era a dos estudos de desenvolvimento. A centralidade dos países mais industrializados no processo de geração e difusão de progresso técnico era uma premissa desses estudos, mesmo que alguns pesquisadores, como Katz (1987), enfatizassem o aprendizado e as inovações incrementais introduzidas ao sul do Equador.

A avaliação da centralidade era mais divisiva. Alguns apontavam a possibilidade de importar tecnologia como uma das vantagens dos late-comers, o que serviria de alavanca para o emparelhamento e para a convergência entre os níveis de renda entre países desenvolvidos e subdesenvolvidos. A falsificação da hipótese de convergência generalizada foi um dos motivadores das teorias do progresso técnico endógeno (Romer, 1990). No desdobramento da teoria, o sucesso de algumas trajetórias nacionais asiáticas, no sentido da convergência, foi interpretado como uma resultante de fatores institucionais, por exemplo, o investimento em capital humano e um "clima favorável" aos investimentos (Rodriguez, Dahlman \& Salmi, 2008). Ou seja, a vantagem dos late-comers é potencial, dependendo de fatores institucionais para se concretizar.

Outros, como os estruturalistas latino-americanos, a exemplo de Furtado (1961), enfatizavam a diferença entre os padrões e as trajetórias de desenvolvimento entre os países industrializados e em desenvolvimento e apontavam as desvantagens decorrentes do uso, no processo de substituição de importações na periferia, dessa tecnologia, desenvolvida para resolver problemas econômicos e sociais de contextos tão diferentes como os do centro. Essas desvantagens se traduziriam em um estilo de desenvolvimento marcado pela tendência ao baixo crescimento econômico, desigualdade na distribuição de riqueza e renda, baixa competitividade internacional e dominação externa. A incapacidade nos países latino-americanos de "abrir a caixa-preta do progresso técnico", associada à insuficiência de incorporação desse progresso, seria, mais tarde, apontada como o "traço central do processo de desenvolvimento latino-americano" (Fajnzylber, 2000, p. 857), processo caracterizado, então, por baixo crescimento e alta desigualdade.

A divisão anteriormente exposta apontava, no mínimo, para a relevância de se estudar o processo de desenvolvimento científico e tecnológico nos países em desenvolvimento e, a partir dos anos 1970, desenvolveu-se na América Latina grande número de estudos sobre o tema. Essa produção - denominada por Dagnino, Thomas e Davyt (1996) de "pensamento latino-americano sobre ciência, 
tecnologia e sociedade - Placts"- foi fortemente influenciada pelo pensamento desenvolvimentista, notadamente pela preocupação com a dependência externa, e contou com a contribuição de cientistas argentinos (Amílcar Herrera, Jorge Sabato) e brasileiros (J. Leite Lopes).

O triângulo de Sabato-Botana (1968), que comparava as relações entre o sistema produtivo, o científico e o Estado na periferia e no centro, sugerindo que, neste último, as relações entre os vértices eram intensas, enquanto na primeira eram frágeis e estabeleciam-se principalmente com seus correspondentes externos, foi importante instrumento de heurística na pesquisa e na formulação de políticas dos anos 1970. A perda de peso da questão da dependência na agenda política e o surgimento de conceitos como a hélice tripla ${ }^{13}$ e o sistema nacional de inovações levaram ao ocaso do triângulo. No entanto, conforme será visto com mais detalhe a seguir, o sumário diagnóstico que fazia ainda é pertinente, mesmo se as soluções que advogava não o sejam. Da mesma forma, a distinção entre políticas implícitas e explícitas de ciência e tecnologia feita por Herrera (1971) foi fecunda e continua a ser utilizada no presente.

Posteriormente, já constatada a emergência do paradigma técnico-econômico-institucional da eletrônica, Perez $(1986,2001)$ e Perez e Soete (1988) argumentariam que os países em desenvolvimento encontrariam "janelas de oportunidade" não só nas tecnologias "maduras", consagradas nas teorias de ciclo de produto e de vantagens dos late- $\mathrm{Co}$ mers, como também nas "novas" tecnologias, em que não estariam atados pelos custos afundados nas antigas práticas tecnológicas, econômicas e institucionais. A exploração dessas "janelas de oportunidade" dependia, porém, de um conjunto de condições não triviais, como a existência de recursos humanos qualificados, um empresariado capaz de identificar e explorar as oportunidades e um Estado dotado da mesma visão de longo prazo e capaz de realizar os investimentos necessários na infraestrutura científica e tec- nológica e de coordenar os atores privados na direção desejada ${ }^{14}$. Não é surpreendente que poucos países em desenvolvimento, localizados na Ásia, tenham logrado se inserir competitivamente no paradigma eletrônico.

As diferenças existentes entre sistemas de inovação ao norte e ao sul do Equador são um tema constante da literatura neo-schumpeteriana, a começar pelo conceito: como apontam Arocena e Sutz (2003), ao norte, esse é um conceito ex-post, elaborado a partir da análise de processos já existentes e que, portanto, combina elementos descritivos e normativos, ao passo que, ao sul, é um conceito ex-ante, de natureza essencialmente normativa ${ }^{15}$. Conforme veremos a seguir, o sistema brasileiro de inovações foi caracterizado como "imaturo" (Albuquerque, 1999) e por um aprendizado essencialmente "passivo" (Viotti, 2001).

O desenvolvimentismo latino-americano foi, como se sabe, tragado pelo tsunami liberal dos anos 1990. Não obstante, encontra vários pontos de contato com o programa de pesquisas evolucionista neo-schumpeteriano. A visão de Perez e Soete (1988, p. 459), de que "um processo real de catching up só pode ser realizado através da aquisição da capacidade de participar na geração e melhorias de tecnologias, em oposição ao seu simples "uso", é recorrente na literatura brasileira dos anos 1970 (Erber, 1979). Na literatura recente, alguns desses pontos de convergência são destacados por Cassiolato e Lastres (2005), que enfatizam a importância, nos dois programas de pesquisa, da especificidade das trajetórias nacionais, das diferenças nas estruturas produtivas e da intervenção do Estado para o desenvolvimento de capacidades tecnológicas, com um viés pró-emprego ${ }^{16}$. Albuquerque (2007) também faz a conexão entre as duas abordagens, destacando o lado da distribuição de renda desigual nos países latino-americanos e sugerindo que um sistema nacional de inovações deveria ser orientado principalmente para resolver os problemas de bem-estar das populações de baixa renda, argumento ampliado em Dagnino (2008).
13 Etzkowtiz e Mello (2004) comparam o triângulo de Sabato -Botana com a hélice tripla, apontando que, no primeiro, cabia ao Estado o pape primordial para que as relações virtuosas entre os vértices fos sem estabelecidas uma abordagem "de cima para baixo" -, ao passo que, na segunda, a liderança cabe às empresas e às universidades, em uma abordagem "debaixo para cima".

14 Perez e Soete (1988) apresentam uma análise detalhada das condições de entrada e crescimento nas diversas fases de um paradigma técnico-econômico-institucional.

150 mesmo fato pode ser dito a respeito do triângulo de Sabato-Botana e da hélice tripla.

16 A convergência entre o pensamento neo-schumpeteriano e asideias de Celso Furtado é discutida em Guimarães, Peixoto Cassiolato e Lastres (2007). Borja (2008) analisa em detalhe o papel da tecnologia no pensamento de Furtado. 
17 Entre outros resultados deletérios para o investimento em inovação, a política macro reduziu drasticamente os recursos dos fundos setoriais.

18 Até então se contava com a base de dados desenvolvida pela Anpei, cujo painel de 365 empresas reunia informações sobre pesquisa e desenvolvimento (P\&D) e engenharia não rotinei$\mathrm{ra}$, seguindo a metodologia da National Science Foundation dos Estados Unidos, ou seja, adotando um conceito mais restrito de inovação, e os estudos feitos em 1996-98 pela Fundação Sistema Estadual de Análise de Dados (Seade) para o estado de São Paulo - Pesquisa da Atividade Econômica Paulista (Paep) e para um conjunto restrito de empresas em outros estados. A seguir, examinam-se os estudosfeitos com essas bases. Informações mais detalhadas sobre as pesquisas podem, naturalmente, ser encontradas nos sites das instituições responsáveis.
No entanto, mesmo no Brasil, onde houve forte produção de estudos sobre o desenvolvimento tecnológico local, inexistiram, até recentemente, instrumentos abrangentes de mensuração do fenômeno, que ficou restrito principalmente a análises qualitativas (Erber, 1979). A disponibilidade de informações abrangentes, notadamente a partir da Pesquisa de Inovação Tecnológica (Pintec), feita pelo IBGE, viria a permitir contornar, pelo menos em parte, esse problema, estimulando uma nova safra de estudos, que, entre outros resultados, permitiram detalhar a especificidade das condições nacionais, conforme é discutido em outro momento.

\section{LEGITIMIDADE POLÍTICA}

Ao longo do período desenvolvimentista-autoritário (1964-79), na apta caracterização de Bielschowsky e Mussi (2005), o crescimento econômico e o aumento da soberania nacional - tendo como hipérbole o "Brasil potência" - constituíram importantes elementos de legitimação do regime. Nesse contexto, faziam parte da estratégia econômica e política do regime a constituição de um sistema científico e tecnológico e a maior capacitação tecnológica das empresas industriais, por meio da interferência estatal, para a qual foram estabelecidas instituições específicas (Guimarães, Araújo Jr. \& Erber, 1985). Como parte desse processo, houve forte engajamento de instituições federais em atividades de pesquisa sobre o desenvolvimento científico e tecnológico brasileiro com destaque, inicialmente, para o Instituto de Pesquisa Econômica Aplicada (Ipea) e, a seguir, para a Financiadora de Estudos e Projetos (Finep).

No entanto, como sugere a resenha feita quase ao fim do período (Erber, 1979), a capacidade tecnológica do parque industrial brasileiro concentrava-se na fabricação e na engenharia de detalhe. $\mathrm{O}$ lançamento de novos produtos e a introdução de novos processos tendiam a apoiar-se na importação de tecnologia. Ao abrir a "caixa-preta" da tecnologia, verificou-se que sua importação levava, inequivocamente, a um aprendizado, mas que não alcançava, espontaneamente, as atividades tecnológicas mais complexas, necessárias para inovações que não fossem incrementais. Nesse panorama, algumas empresas estatais destacavam-se, mercê de sua ambiguidade estrutural, ao serem, ao mesmo tempo, empresas e Estado.

Durante as décadas de 1980 e 1990, a agenda econômica e política foi dominada pelas questões de estabilização e reformas institucionais. Sintomaticamente, o Centro de Pesquisas da Finep foi fechado, e a pesquisa sobre o tema ficou exclusivamente nas mãos da academia. A visão hegemônica era de que a abertura se encarregaria do processo de inovação - diretamente, pela importação de bens de capital e intermediários mais modernos e pela entrada do investimento direto estrangeiro, e indiretamente, pela pressão competitiva exercida por esses fatores. Não obstante o otimismo sobre o bom funcionamento dos mercados, o rumo da economia permaneceu incerto, como veremos a seguir, relegando a questão da inovação a um plano secundário. Mesmo assim, aparatos estatais funcionalmente encarregados do desenvolvimento científico e tecnológico continuaram a fomentar alguns estudos, entre os quais se destaca o feito sobre a competitividade da indústria brasileira (Coutinho \& Ferraz, 1994).

Nos anos seguintes, diversos estudos centrados no conteúdo tecnológico das importações e exportações brasileiras apontaram para a natureza estrutural do déficit comercial do país, dado que as exportações brasileiras eram concentradas em produtos de baixo conteúdo tecnológico, intensivas em recursos naturais, ao passo que as importações eram concentradas em produtos de alta e média intensidade tecnológica. Como a elasticidade-renda da demanda mundial pelos produtos exportados pelo Brasil era menor que a elasticidade-renda dos produtos importados pelo Brasil, qualquer aumento da taxa de crescimento do nosso produto interno bruto (PIB) tendia a agravar a restrição externa (Gonçalves, 2000; Erber, 2001). Essa 
literatura ficou, porém, relegada ao limbo da heterodoxia, com limitado efeito de encadeamento na academia e nenhuma consequência na política de inovação.

Já no início da década, o Ministério da Ciência e Tecnologia (MCT) patrocinou, em colaboração com a Academia Brasileira de Ciências (ABL), a Conferência Nacional de Ciência, Tecnologia e Inovação, da qual resultaram um Livro Verde (Silva \& Melo, 2001) e um Livro Branco (MCT, 2002) sobre ciência, tecnologia e inovação e estabeleceu novo mecanismo institucional de apoio à inovação - os fundos setoriais. Não obstante, a turbulência macroeconômica do início da década e as políticas macroadotadas ${ }^{17}$ relegaram a inovação a um baixo nível de prioridade na agenda de políticas públicas. Do ângulo mais restrito da produção acadêmica, duas ações do MCT e da Finep mostraram-se muito frutíferas: o lançamento da Revista Brasileira de Inovação, que não só publica textos recentes, mas também divulga artigos "clássicos" sobre o tema, e o estímulo, intelectual e financeiro, ao IBGE, para que realizasse a primeira Pintec, uma inovação radical nas estatísticas brasileiras sobre inovação.

O quadro mudou em 2003. O novo governo, dando seguimento ao enunciado em seu programa eleitoral, anunciou no fim do ano as Diretrizes da Política Industrial, Tecnológica e de Comércio Exterior (Pitce). Apresentada em um ano em que a política macroeconômica era restritiva, o crescimento baixo e a restrição externa ainda não havia sido levantada pelo boom de commodities alavancado pela China, a Pitce tinha importante valor simbólico de comprometimento com o crescimento. Apresentava, ainda, pela primeira vez na história brasileira, a explícita articulação entre as três políticas constantes do seu título. O fulcro dessa articulação era dado pela inovação, seja por meio da escolha de setores prioritários (bens de capital, softwa$r e$, componentes eletrônicos e fármacos), caracterizados por apresentarem fortes déficits comerciais e serem intensivos em tecnologia, seja na prioridade dada a novas tecnologias, de natureza transversal, como a biotecnolo- gia e a nanotecnologia, seja pela ampliação das medidas de estímulo fiscal e creditício para a inovação, de corte horizontal.

A ênfase política dada à inovação coincidiu com a divulgação da Pintec, feita pelo $\mathrm{IBGE}^{18}$. A Pintec segue as normas internacionais de mensuração da inovação, definidas no Manual de Oslo, antes mencionado, e constitui uma inovação radical em termos de mensuração da inovação no Brasil. As informações solicitadas referem-se às características da empresa; às inovações de produto e processo implementadas, incompletas ou abandonadas; às atividades inovadoras desenvolvidas, aos gastos com essas atividades e ao financiamento desses gastos; ao caráter das atividades internas de P\&D e número, qualificação e dedicação das pessoas envolvidas; aos impactos da inovação no valor das vendas e exportações; às fontes de informação utilizadas; aos arranjos cooperativos estabelecidos com outra organização; ao apoio do governo; às patentes e outros métodos de proteção; aos problemas encontrados; e às mudanças organizacionais empreendidas no período da pesquisa.

O presidente do Ipea, Glauco Arbix, e o diretor de Estudos Setoriais, Mario Salerno, tiveram papel fundamental na elaboração da Pintec. A seguir, a mesma diretoria organizou, sob a coordenação de João De Negri, um banco de dados, inédito no país, combinando os microdados da Pintec com várias outras bases de informação ${ }^{19}$. Esse rico banco de dados foi utilizado para grande número dos estudos, feitos por técnicos do Ipea ou encomendados pelo Ipea a pesquisadores acadêmicos. Da mesma forma, a Finep e o Centro de Gestão e Estudos Estratégicos patrocinaram estudos e seminários sobre diversos aspectos do processo de inovação no Brasil, acessíveis nos sites respectivos. Além das instituições federais, entidades estaduais, notadamente, a Fundação Seade e o Instituto de Pesquisas Tecnológicas do Estado de São Paulo, também realizaram pesquisas sobre inovação. Instituições privadas vinculadas à indústria, como a Associação Nacional de Pesquisa, Desenvolvimento e Engenharia das
19 Pesquisa Industrial Anual(PIA)e Pesquisa Nacional por Amos tra de Domicílios (PNAD) do Instituto Brasileiro de Geografia eEstatística (IBGE), da Relação Anual de Informações Sociais do Ministério do Trabalho e Emprego, de Comércio Exterior do Ministério do Desenvolvimento Indústria e Comércio do Censo de Capitais Estrangeiros e de capitais brasileiros no exterior do Banco Central do Brasil (Bacen) e das compras governamentais do MinistériodoPlanejamento, Orçamento e Gestão. Araiz deligação entre essas bases dedadoséo Cadastro Nacional da Pessoa Jurídica (CNPJ) dasfirmas. As informações têm periodicidade anual e abarcam o período 1996 a 2002, estimando-se que cubram mais de $95 \%$ do valor adicionado na indústria ( $\mathrm{De}$ Negri, Freitas, Costa Silva \& Alves, 2005). 
20 Uma nota de história institucional da pesquisa sobre inovação no Brasil, motivada pela notória falta de memórianacional.Os dois trabalhos feitos pelo setor de indústria do Ipea/Instituto de Planejamento da GestãoGovernamental (Iplan) (Biato, Guimarães \& Figueiredo, 1971 e 1973) sobre, respectivamente, o potencial de pesquisa tecnológico e a transferência de tecnologia para o Brasil constituem o marco inicial de pesquisa econômica sobre a especificidade brasileira. Foram, até o estudo de Matesco (1993), usando os dados do Censo de 1985 e, a seguir, a Pesquisa de Atividade Regional (Paer) e a Pintec, os únicos de caráter abrangente. $\mathrm{O}$ afastamento do Ipea do tema foi fator importante para a criação do Grupo de Pesquisas da Finep, principal centro especializado nessa área durante os anos 1970.
Empresas Inovadoras (Anpei), o Instituto de Estudos para o Desenvolvimento Industrial (Iedi), a Confederação Nacional da Indústria (CNI), a Federação das Indústrias do Estado do Rio de Janeiro (Firjan) e a Federação das Indústrias do Estado de São Paulo (Fiesp), também encomendaram e divulgaram estudos sobre o tema.

Portanto, a partir de 2004, havia um conjunto de fatores favoráveis ao estudo da inovação no Brasil: a legitimidade acadêmica no plano internacional, a prioridade política concedida ao tema no Brasil, o engajamento direto da principal instituição de pesquisa do governo federal ${ }^{20}$ e de um importante conjunto de instituições públicas e privadas que mobilizaram um expressivo contingente de pesquisadores na academia e, finalmente, a disponibilidade de uma nova base de dados, elaborada segundo normas internacionais permitindo comparações com outros países -, apta a ser tratada com métodos quantitativos modernos, estimulando o interesse de gerações mais novas de pesquisadores.

\section{ALBUQUERQUE, E. Patentes Domésticas: Avaliando Estatísticas Internacionais para Localizar o Caso Brasileiro. Cedeplar, 1999 (Texto para Discussão n. 126). . "Inadequacy of the Technology and Innovation Systems at the Periphery", in Cambridge Journal of Economics, v. 31, 2007. \\ AROCENA, R.; SUTZ, J. Subdesarrollo e Innovación: Navegando Contra el Viento. Madrid,} Cambridge University Press, 2003.

BIATO, F.; GUIMARÃES, E.; FIGUEIREDO, M. Potencial de Pesquisa Tecnológica no Brasil.

Rio de Janeiro, Ipea/Iplan, 1971 (Relatório de Pesquisa no 5). . A Transferência de Tecnologia no Brasil. Rio de Janeiro, Ipea/Iplan, 1973

(Estudos para o Planejamento $\mathrm{n}^{\circ}$ 4).

BIELSCHOWSKY, R.; MUSSI, C. O Pensamento Desenvolvimentista no Brasil 1930-964

e Anotações sobre o Período 1964-2005. Brasília, Cepal, 2005. Mimeografado.

BORJA, B. O Sentido da Tecnologia: a Teoria do Subdesenvolvimento de Celso Furtado.

Tese de mestrado. IE/UFRJ, 2008.

CASSIOLATO, J.; LASTRES, H. "O Foco em Arranjos Produtivos Locais de Micro e Pequenas

Empresas", in H. Lastres; J. Cassiolato; M. Maciel (orgs.). Pequena Empresa: Cooperação e

Desenvolvimento Local. Rio de Janeiro, Relume Dumará, 2003.

. "Sistema de Inovação e Desenvolvimento: as Implicações de Política",

in São Paulo em Perspectiva, v. 19, oㅜ 1, 2005.

COUTINHO, L.; FERRAZ, J. Estudo da Competitividade da Indústria Brasileira. Campinas,

Papirus/Editora Unicamp, 1994.

DAGNINO, R. "A Relação Universidade-empresa no Brasil e o 'Argumento da Hélice Tripla"', in Convergência, no 76, 2004.

. "Por que os 'Nossos' Empresários Não Inovam?", in Boletim de Economia e Tecnologia. Departamento de Economia da UFPR, jul./2008.

DAGNINO, R.; THOMAS, H.; DAVYT, P. “El Pensamiento en Ciencia, Tecnología y Sociedad en Latinoamérica: una Interpretación Política de su Trayectoria", in Redes, v. 3, oㅡ 7, 1996.

DALHMAN, C.; FRISCHTAK. "Os Desafios do Brasil da Economia do Conhecimento:

Educação e Inovação num Mundo Crescentemente Competitivo", in J. P. Reis Velloso (org.). Reforma Política e Economia do Conhecimento: Dois Projetos Nacionais.

Rio de Janeiro, José Olympio, 2005. 
DE NEGRI, F. "Padrões Tecnológicos e de Comércio Exterior das Firmas Brasileiras", in J.

De Negri; M. Salerno (orgs.). Inovações, Padrões Tecnológicos e Desempenho das Firmas Industriais Brasileiras. Brasília, Ipea, 2005

DE NEGRI, J.; FREITAS, F.; COSTA, G.; SILVA, A.; ALVES, P. “Tipologia das Firmas Integrantes da Indústria Brasileira", in J. De Negri; M. Salerno (orgs.). Inovações, Padrões Tecnológicos e Desempenho das Firmas Industriais Brasileiras. Brasília, Ipea, 2005.

DOSI, G. "Technological Paradigms and Technological Trajectories: a Suggested Interpretation of the Determinants and Directions of Technical Change", in Research Policy, v. 11, 1982.

ERBER, F. "Política Científica e Tecnológica no Brasil: uma Revisão da Literatura", in J. Sayad (org.). Resenhas da Economia Brasileira. São Paulo, Saraiva, 1979. "Desenvolvimento Industrial e Tecnológico na Década de 90 - uma Nova Política para um Novo Padrão de Desenvolvimento", in Ensaios FEE, ano 13, no 1, 1992. . "O Padrão de Desenvolvimento Industrial e Tecnológico e o Futuro da Indústria Brasileira", in Revista de Economia Contemporânea, v. 5, edição especial, 2001. ETZKOWITZ, H.; MELLO, J. "The Rise of the Triple Helix Culture: Innovation in Brazilian Economic and Social Development", in International Journal of Technology Management \& Sustainable Development, v. 2, no 3, 2004.

FAPESP. Indicadores de Ciência, Tecnologia e Inovação em São Paulo - 2001. São Paulo, Fundação de Amparo à Pesquisa do Estado de São Paulo, 2002.

FAJNZYLBER, F. "Industrialização na América Latina: da 'Caixa-preta' ao 'Conjunto Vazio'", in R. Bielschowsky (org.). Cinquenta Anos de Pensamento na Cepal. Rio de Janeiro, Record, 2000. FERRAZ, J.; KUPFER, D.; HAGUENAUER, L. Made in Brazil: Desafios Competitivos para a Indústria. Rio de Janeiro, Campus, 1996.

FREEMAN, C. The "'National System of Innovation' in Historical Perspective", in Cambridge Journal of Economics, v. 19, 1995.

FURTADO, C. Desenvolvimento e Subdesenvolvimento. Rio de Janeiro, Fundo de Cultura, 1961. GONÇALVES, R. O Brasil e o Comércio Internacional: Transformação e Perspectivas. São Paulo, Contexto, 2000.

GUIMARÃES, E.; ARAÚJO JR., J.; ERBER, F. A Política Científica e Tecnológica. Rio de Janeiro, Jorge Zahar, 1985.

GUIMARÃES, V.; PEIXOTO, F.; CASSIOLATO, J.; LASTRES, H. “Convergências e Complementaridades da Corrente Neo-schumpeteriana com o Pensamento Estruturalista de Celso Furtado", in J. Sabóia; F. Carvalho (orgs.). Celso Furtado e o Século XXI. Barueri, Manole, 2007.

HERRERA, A. Ciência y Política en América Latina. México, Siglo Veintiuno Editores, 1971. JOHNSON, H. "Comparative Cost and Commercial Policy Theory", in Wicksell Lectures, 1968. "The State of Theory in Relation to the Empirical Analysis", in R. Vernon (org.). The Technology Factor in International Trade. New York, Columbia University Press, 1970.

KATZ, J. Technology Generation in Latin-american Manufacturing Industries. Londres,Macmillan, 1987.

LAKATOS, I. "Falsification and Methodology of Scientific Research Programmes", in I. Lakatos; A. Musgrave (orgs.). Criticism and the Growth of Knowledge. Londres, Cambridge University Press, 1970.

LANCASTER, K. "A New Approach to Consumer Theory", in Journal of Political Economy, v. 174, 1966.

LANDES, D. The Unbound Prometheus. Cambridge, Cambridge University Press, 1969.

LINDER, S. An Essay on Trade and Transformation. New York, Wiley, 1961. 
LUNDVALL, B.-A. (org.). National Innovation System: Towards a Theory of Innovation and Interactive Learning. Londres, Pinter, 1992.

. National Innovation System: Analytical Focusing Device and Policy Learning Tool. ITPS - Swedish Institute for Growth Policy Studies, 2007 (Working Paper R2007:004).

MALERBA, F.; ORSENIGO, L. Technological Regimes and Sectoral Patterns of Innovative Activities", in Industrial and Corporate Change, v. 6, no 1, 1997.

MATESCO, V. "Atividade Tecnológica das Empresas Brasileiras: Desempenho e Motivação para Inovar", in Perspectivas da Economia Brasileira 1994. Volume 1. Rio de Janeiro, Ipea, 1993.

MCT. Livro Branco: Ciência, Tecnologia e Inovação. Brasília, Ministério da Ciência e Tecnologia, 2002.

NELSON, R. National Innovation Systems: a Comparative Analysis. Oxford, Oxford University Press, 1993.

NORTH. D. Institutions, Institutional Change and Economic Performance. Cambridge, Cambridge University Press, 1990.

PAVITT, K. "Sectoral Patterns of Technical Change: Towards a Taxonomy and a Theory", in Research Policy, v. 13, 1984.

PEREZ, C. "Las Nuevas Tecnologías: una Visión de Conjunto", in C. Ominami (org.). La Tercera Revolución Industrial: Impactos Internacionales del Actual Viraje Tecnológico. Buenos Aires, Grupo Editor Latinoamericano, 1986.

."Technological Change and Opportunities for Development as a Moving Target", in Cepal Review, no 75, dez./2001.

PEREZ, C.; SOETE, L. "Catching up in Technology: Entry Barriers and Wondows for Opportunity", in G. Dosi; C. Freeman; R. Nelson; G. Silverberg; L. Soete (orgs.). Technical Change and Economic Theory. Londres, Pinter Publishers, 1988.

POSNER, M. "International Trade and Technical Change", in Oxford Economic Papers. Out./1961.

RODRIGUEZ, A.; DAHLMAN, C.; SALMI, J. Conhecimento e Inovação para a Competitividade. Brasília, Banco Mundial; Confederação Nacional da Indústria (CNI), 2008.

ROMER, P. "The Origins of Endogenous Growth", in Journal of Economic Perspectives, v. 8, no 1,1990 .

SABATO, J.; BOTANA, N. “La Ciencia y la Tecnología en el Desarrollo Futuro de America Latina", in Revista de la Integración InTAL, v. 1, no 3, 1968.

SCHERER, F. "Interindustry Technology Flows in the United States", in Research Policy, v. 11, 1982.

SILVA, C.; MELO, L. (orgs.). Ciência, Tecnologia e Inovação: Desafio para a Sociedade Brasileira. Livro Verde. Brasília, Ministério da Ciência e Tecnologia e Academia Brasileira de Ciências, 2001.

VERNON, R. "International Investment and International Trade in the Product Cycle", in Quarterly Journal of Economics. Maio/1966.

VILLASCHI, A. "Anos 90: uma Década Perdida para o Sistema Nacional de Inovações Brasileiro?", in São Paulo em Perspectiva, v. 19, no 2, 2005.

VIOTTI, E. “National Learning Systems: a New Approach on Technological Change in Late Industrializing Economies and Evidences from the Cases of Brazil and South Korea. Center for International Development, Harvard University", in Science, Technology and Innovation discussion Paper, ํo 12, 2001. 